\title{
Farinha de Resíduos da Filetagem de Tilápia em Rações para Alevinos de Piauçu (Leporinus macrocephalus)
}

\section{Wilson Rogério Boscolo ${ }^{1}$, Altevir Signor ${ }^{2}$, Aldi Feiden ${ }^{3}$, Arcangelo Augusto Signor ${ }^{4}$, Luciano André Schaefer ${ }^{5}$, Adilson Reidel ${ }^{6}$}

RESUMO - Este experimento foi realizado com o objetivo de avaliar o efeito da inclusão de farinha de resíduos da industrialização de tilápia (FT) na alimentação de alevinos de piauçu (Leporinus macrocephalus). Cento e vinte e cinco alevinos com peso e comprimento iniciais de $0,19 \pm 0,004 \mathrm{~g}$ e 2,37 $\pm 0,2 \mathrm{~cm}$ foram distribuídos em delineamento inteiramente casualizado, com cinco tratamentos e cinco repetições. As rações testadas continham $0 ; 5 ; 10$ e 15\% de FT e 0\% de FT suplementada com metionina. O arraçoamento foi de $10 \%$ da biomassa quatro vezes ao dia $(8,11,14$ e $17 \mathrm{~h})$. As médias dos parâmetros físico-químicos da água foram 7,89 $\pm 0,05,89,93 \pm 0,42$, $7,15 \pm 0,10$ e $27,10 \pm 0,95$ para $\mathrm{pH}$, condutividade elétrica $\left(\mu \mathrm{S} . \mathrm{cm}^{-1}\right)$, oxigênio dissolvido $\left(\mathrm{mg} . \mathrm{L}^{-1}\right)$ e temperatura $\left({ }^{\circ} \mathrm{C}\right)$, respectivamente. Ao final do período experimental, foram avaliadas as médias de sobrevivência (SO), peso final (PF), comprimento final (CF), ganho de peso (GP), fator de condição (FC) e conversão alimentar aparente (CA). Foram observadas diferenças quanto ao CF, CA e FC entre tratamentos, obtendo-se melhores resultados naqueles com inclusão de FT e suplementação de metionina. O CF apresentou aumento linear com platô em $8,56 \%$ de FT e a CA apresentou redução linear com platô de $8,19 \%$ de inclusão de FT. Os maiores teores de proteína bruta (PB) na carcaça foram obtidos nos tratamentos com mais de 5\% de FT e $0 \%$ de FT suplementado com metionina. Pode-se incluir até $15 \%$ de FT em rações para alevinos de piauçu, melhorando seu desempenho e deposição de PB na carcaça, o que torna a FT uma fonte protéica alternativa.

Palavras-chave: desempenho, metionina, nutrição de peixes, resíduos industriais

\section{Effects of Feeding Tilapia By-products Flour for Piauçu (Leporinus macrocephalus) Fingerlings}

\begin{abstract}
This trial was carried out to evaluate the effects of feeding Tilapia fillet by-products meal (TF) for piauçu (Leporinus macrocephalus) fingerlings. One hundred and twenty-five fingerlings averaging weight of $0.19 \pm 0.004 \mathrm{~g}$ and length of $2.37 \pm 0.28 \mathrm{~cm}$ were assigned to a completely randomized design with five treatments of five replicates. The diets were formulated to contain levels of 0,5 , 10 , and $15 \%$ of TF and $0 \%$ of TF plus methionine. Diets were fed at $10 \%$ of biomass four times a day ( 8 a.m., 11 a.m., 2 p.m. and 5 p.m.). The means of water abiotic parameters were $7.89 \pm 0.05,89.93 \pm 0.42,7.15 \pm 0.10$ and $27.10 \pm 0.95$ for $\mathrm{pH}$ and electric conductivity $\left(\mu \mathrm{S} . \mathrm{cm}^{-}\right.$ $\left.{ }^{1}\right)$ and dissolved oxygen $\left(\mathrm{mg} . \mathrm{L}^{-1}\right)$ and temperature $\left({ }^{\circ} \mathrm{C}\right)$, respectively. At the end of the experiment, the means of survival (SO), final weight (FW), final length (FL), weight gain (WG), condiction factor (CF), and apparent feeding conversion (FC) were measured and calculated. Significant effects of treatments on CF, CA, and FC were detected. The better results were observed with the increasing levels of FT and supplementation of methionine. FL increased and FC decreased linearly with the increasing levels of TC, where the LRP model better adjusted to data when 8.56 and $8.19 \%$ of TF levels were estimated. The crude protein (PB) in the carcass presented better results for the treatments with more than $5 \%$ of FT and $0 \%$ of FT with methionine supplementation. It is recommended to include up to $15 \%$ of FT in the diets for piauçu fingerlings to obtain better results of performance and CP deposition in the carcass, that becomes the FT an alternative protein source.
\end{abstract}

Key Words: industry by-products, fish nutrition, methionine, performance

\section{Introdução}

A família dos Anastomideos pertence à ordem Characiformes, sendo o gênero Leporinus o mais complexo desta família, principalmente em razão do grande número de espécies descritas (aproximadamente 60) (Spi, 1829; Garavelo \& Britski, 1988, citados por
Ribeiro (1999), da ampla distribuição geográfica e da grande importância para a pesca esportiva e comercial, principalmente as espécies L. macrocephalus, L. friderici, L. obtusidens e L. elongatus.

O gênero Leporinus compreende espécies de grande potencial para a aqüicultura, com significativa importância para a pesca extrativa na região do Rio

\footnotetext{
1 Zootecnista, Professor Adjunto do curso de Engenharia de Pesca - UNIOESTE - Campus Toledo - PR. E.mail: wrboscolo@unioeste.br 2 Engenheiro de Pesca - Mestrando - CAUNESP-UNESP - Jaboticabal - SP. E.mail: altevirsignor@bol.com.br

${ }^{3}$ Agrônomo, Professor Adjunto do curso de Engenharia de Pesca - UNIOESTE - Campus Toledo - PR. E.mail: aldi@unioeste.br

${ }^{4}$ Acadêmico do curso de Engenharia de Pesca da UNIOESTE - Campus Toledo - PR. Bolsista PIBIc/CNPq. E.mail: aasignor@pop.com.br

${ }^{5}$ Engenheiro de Pesca.

${ }^{6}$ Engenheiro de Pesca, Doutorando em Aqüicultura - CAUNESP - Jaboticabal-SP. E.mail: reidel@unioeste.br
} 
Paraná, atingindo porte de médio a grande, com bom valor comercial, ocorrendo em grande quantidade nos rios e reservatórios. No entanto, torna-se necessário o conhecimento dos aspectos biológicos e produtivos das espécies que congregam este gênero, sobretudo a L. macrocephalus, para o aproveitamento racional de seu potencial piscícola, sendo fundamental o conhecimento das exigências nutricionais e do valor biológico dos alimentos para formulação de rações que proporcionem bom desempenho aos peixes.

O piauçu (L. macrocephalus) é caracterizado como espécie de hábito alimentar onívoro que aceita em sua dieta ampla gama de alimentos (Silva, 1988; Andrian et al., 1994) e pode atingir 7,5 kg (Silva, 1988), sendo considerada de grande potencial comercial, por apresentar crescimento rápido nas fases iniciais, rusticidade ao manejo e resistência às variações de temperatura. Entretanto, são raras as pesquisas para determinação de suas exigências nutricionais, de manejo e profilaxia (Soares, 1997; Soares et al., 2000).

Com a expansão da atividade de "pesque-pague", procuram-se espécies adaptadas à pesca esportiva, destacando-se o piauçu (Hayashi et al., 1999a), pela agressividade quando capturado e pela carne, que possui ótimas características organolépticas. Um entrave para a expansão do cultivo do piauçu é o fato de esta espécie não ser apropriada para a indústria de filetagem, por apresentar espinhos em forma de "Y" em sua musculatura. Entretanto, a remoção das espinhas intramusculares, utilizando-se o processo de despolpagem, para elaboração de produtos específicos, como bolinhos, fishburgers e análogos de pescados (Antunes, 1997), pode incrementar sua produção, viabilizando ainda mais seu cultivo pela criação de um novo mercado consumidor.

Os alimentos protéicos representam a maior proporção dos custos da ração em sistemas intensivo e semi-intensivo, pois, além de participarem em grande quantidade na ração, são mais caros que os alimentos energéticos (Millamena, 2002; Meurer et al., 2003; Boscolo, 2003; Furuya et al., 2004; Signor et al., 2004).

Os resíduos da industrialização da tilápia representam de 60 a $70 \%$ da matéria-prima utilizada para produção de filés. Esses resíduos são atualmente subutilizados ou descartados pelas indústrias de filetagem, pelo desconhecimento do seu potencial como alimento para peixes (Boscolo, 2003). A falta de recursos para aquisição de equipamentos industriais e/ou de pesquisa pode ocasionar a utilização descontrolada e problemas com a qualidade de água.
A substituição de fontes tradicionais de proteína por alimentos alternativos é uma forma de utilização de resíduos industriais muito importante para a redução dos custos do pescado, visto que a proteína é o nutriente responsável pela maior parcela dos custos de produção (Pezzato et al., 2002; Meurer et al., 2003; Boscolo et al., 2004). Entretanto, não há estudos sobre os níveis de exigência e a composição química para dessa fonte protéica para o piauçu (L. macrocephalus).

Neste experimento, objetivou-se determinar o efeito da inclusão de farinha de resíduos da filetagem de tilápias e da suplementação de metionina sintética na alimentação sobre o desempenho e a composição química da carcaça de alevinos de piauçu (L. macrocephalus).

\section{Material e Métodos}

O experimento foi realizado no período de cinco de dezembro de 2003 a 14 de janeiro de 2004, no Laboratório de Aqüicultura da Universidade Estadual do Oeste do Paraná - Campus de Toledo. Foram utilizados 125 alevinos de piauçu (L. macrocephalus) com peso e comprimento iniciais de $0,19 \pm 0,004 \mathrm{~g}$, $2,37 \pm 0,28 \mathrm{~cm}$, respectivamente, e aproximadamente 30 dias de idade, distribuídos em um delineamento inteiramente casualizado, com cinco tratamentos e cinco repetições, em 25 aquários de 30 L (volume útil). Cada aquário com cinco peixes foi considerado uma unidade experimental.

Os aquários, dotados de aeração constante e individual, por meio de mangueiras ligadas a um soprador de ar central, foram sifonados duas vezes ao dia, pela manhã e à tarde, antes da primeira e última alimentação, com retirada e reposição de $40 \%$ do volume de água.

Os parâmetros físico-químicos da água dos aquários (oxigênio dissolvido, $\mathrm{pH}$ e condutividade elétrica) foram mensurados semanalmente, pela manhã, antes da sifonagem e a temperatura foi coletada diariamente, de manhã e à tarde.

A farinha do resíduo de indústria de filetagem de tilápias foi obtida de uma indústria de filetagem de tilápias da região oeste do Paraná, sendo composta de cabeça, pele, escamas, nadadeiras, vísceras e coluna vertebral. Sua composição e os valores de digestibilidade aparente foram estimados segundo Boscolo (2003). 
As rações, isofosfóricas e isocálcicas com base em nutrientes digestíveis propostos por Boscolo et al. (2002a), foram formuladas para conterem $30 \%$ de proteína digestível e $3.080 \mathrm{kcal} / \mathrm{kg}$ de energia digestível (Pezzato et al., 2002; Boscolo et al., 2002; Meurer et al., 2003; Boscolo, 2003), sendo as mesmas tendo como fonte de variação a inclusão da FT em $0 ; 5 ; 10$ e $15 \%$ de FT e $0 \%$ de FT suplementada com DL-metionina 99\%, de modo a apresentar o mesmo nível de metionina da ração com $15 \%$ de FT. Para a elaboração das rações, os alimentos foram processados em moinho tipo faca com peneira de malha $0,5 \mathrm{~mm}$ e misturados manualmente. Posteriormente, as rações foram peletizadas, conforme metodologia descrita por Hayashi et al. (1999b). A composição percentual das rações experimentais encontra-se na Tabela 1 e a composição química, na Tabela 2.

$\mathrm{O}$ arraçoamento foi realizado quatro vezes ao dia, às $8,11,14$ e $17 \mathrm{~h}$, em proporção equivalente a $10 \%$ do peso vivo. Para manutenção da porcentagem de arraçoamento, foram realizadas biometrias semanais por meio da pesagem dos alevinos, para aferição da quantidade de ração a ser fornecida, acrescentandose $5 \%$ sobre seu peso a cada três dias.

Ao final do experimento, os peixes de cada unidade experimental ficaram 12 horas em jejum para o esva- ziamento do trato digestório. Foram contados, pesados e medidos, para o cálculo das médias de sobrevivência (SO), peso final (PF), comprimento final ( $\mathrm{CF}$ ), ganho de peso (GP), conversão alimentar aparente (CA) e fator de condição (FC). Os peixes de cada unidade experimental foram congelados para posteriores análises de composição química, segundo Silva (1990).

Os dados obtidos foram submetidos à análise de variância a 5\% de significância e, em caso de diferenças, foi realizada análise de regressão, LRP (Linear Response Plateau) e teste Duncan, de acordo com o Programa Estatístico Computacional SAEG (Sistema de Análises Estatísticas e Genéticas) (UFV, 1997).

\section{Resultados e Discussão}

Ao final do experimento, os valores dos parâmetros físico-químicos da água foram de 7,89 $\pm 0,05,89,93 \pm$ $0,42,7,15 \pm 0,10$ e $27,10 \pm 0,95$ para $\mathrm{pH}$, condutividade elétrica $\left(\mu \mathrm{S} . \mathrm{cm}^{-1}\right)$, oxigênio dissolvido $\left(\mathrm{mg} . \mathrm{L}^{-1}\right)$ e temperatura $\left({ }^{\circ} \mathrm{C}\right)$, respectivamente, e encontram-se dentro do recomendado por Boyd (1990) e Sipaúba-Tavares (1995).

Os valores médios de desempenho, sobrevivência, conversão alimentar aparente e fator de condição encontram-se na Tabela 3.

O PF, GP e SO não apresentaram diferenças entre os tratamentos, o que confirma os dados observados

Tabela 1 - Composição percentual dos ingredientes das rações experimentais Table 1 - Ingredient composition (\%) of experimental diets

\begin{tabular}{|c|c|c|c|c|c|}
\hline \multirow[t]{2}{*}{$\begin{array}{l}\text { Ingrediente } \\
\text { Ingredient }\end{array}$} & \multicolumn{5}{|c|}{$\begin{array}{l}\text { Inclusão de farinha de tilápia (FT) } \\
\text { Inclusion of tilapia by-products (FT) }\end{array}$} \\
\hline & $0 \%$ & $5 \%$ & $10 \%$ & $15 \%$ & $0 \%+$ Met \\
\hline Antioxidante (BHT) (Antioxidant BHT) & 0,02 & 0,02 & 0,02 & 0,02 & 0,02 \\
\hline Calcário calcítico (Limestone) & 2,00 & 1,33 & 0,67 & 0,0 & 2,00 \\
\hline DL-metionina 99\% (DL-methionine 99\%) & 0,0 & 0,0 & 0,0 & 0,0 & 0,08 \\
\hline Farinha de resíduo de tilápia (Tilapia by-products meal) & 0,00 & 5,00 & 10,00 & 15,00 & 0,00 \\
\hline Farelo de trigo (Wheat meal) & 14,3 & 16,79 & 19,26 & 21,73 & 14,25 \\
\hline Milho (Corn) & 12,00 & 13,37 & 14,74 & 16,10 & 11,99 \\
\hline Óleo de soja (Soybean oil) & 3,87 & 2,58 & 1,29 & 0,0 & 3,87 \\
\hline Suplemento (min.+vit. $)^{1}($ Min. + vit. supplement $)$ & 1,00 & 1,00 & 1,00 & 1,00 & 1,00 \\
\hline $\operatorname{Sal} \operatorname{comum}($ Salt $)$ & 0,50 & 0,50 & 0,50 & 0,50 & 0,50 \\
\hline
\end{tabular}

${ }^{1}$ Níveis de garantia por quilograma do produto: Vit. A, 500.000Ul; Vit. D, 200.000 UI; Vit. E, 5.000 mg; Vit. K3, 1.000 mg; Vit. B1, 1.500 mg; Vit. B2, 1.500 mg; Vit. B6, 1.500 mg; Vit. B12, 4.000 mg; Ác. Fólico, 500 mg; Pantotenato Ca, 4.000 mg; Vit. C, 15.000 mg; Biotina, 50 mg; Inositol, 10.000; Nicotinamida, 7.000; Colina, 40.000 mg; Co, 10 mg; Cu, 500 mg; Fe, 5.000 mg; I, 50 mg; Mn, 1500 mg; Se, 10 mg; $\mathrm{Zn}, 5.000 \mathrm{mg}$.

${ }^{1}$ Levels of guarantee for kilogram of the product: Vit. A , 500,000 UI; Vit. D3, 200,000Ul; Vit. E, 5,000 mg; Vit. K3, 1,000 mg; Vit. B1, 1,500 mg; Vit. B2, 1,500 mg; Vit. B6, 1,500 mg; Vit. B12, 4,000 mg; Folic acid, $500 \mathrm{mg}$; Ca pantotenate, 4,000 mg; Vit. C, 15,000 mg; Biotine, 50 mg; Inositiol, 10,00; Nicotinamide, 7,000; Hill, 40,000 mg; Co, 10 mg; Cu, 500 mg; Fe, 5, 000 mg; I, 50 mg; Mn, 1,500 mg; If, 10 mg; Zn, 5,000 mg. 
Tabela 2 - Composição química das rações experimentais

Table 2 - Chemical composition of experimental diets

Nutriente (\%)

Nutrient

Inclusão de farinha de tilápia (FT)

Inclusion of tilapia by-products (FT)

\begin{tabular}{|c|c|c|c|c|c|}
\hline & $0 \%$ & $5 \%$ & $10 \%$ & $15 \%$ & $0 \%+$ Met \\
\hline Energia digestivel $(\mathrm{kcal} / \mathrm{kg})^{1}$ (Digestible energy) & 3.069 & 3.069 & 3.068 & 3.068 & 3.067 \\
\hline Proteina bruta $^{2}$ (Crude protein) & 33,52 & 33,54 & 33,55 & 33,57 & 33,55 \\
\hline Proteína digestível $^{2}$ (Digestible protein) & 30,00 & 29,99 & 29,99 & 29,99 & 29,99 \\
\hline Gordura (Fat) & 5,62 & 5,47 & 5,33 & 5,185 & 5,62 \\
\hline Fibra bruta (Crude fiber) & 5,33 & 5,21 & 5,08 & 4,96 & 5,33 \\
\hline Amido (Starch) & 20,45 & 21,19 & 21,93 & 22,67 & 20,42 \\
\hline Fosforo total (Total phosphorus) & 0,88 & 0,89 & 0,91 & 0,93 & 0,87 \\
\hline Cálcio (Calcium) & 1,32 & 1,32 & 1,32 & 1,32 & 1,32 \\
\hline Linoléico (Linoleic acid) & 2,99 & 2,32 & 1,65 & 0,98 & 2,99 \\
\hline Lisina (Lysine) & 1,91 & 1,91 & 1,911 & 1,91 & 1,91 \\
\hline Metionina (Methionine) & 0,47 & 0,49 & 0,52 & 0,54 & 0,55 \\
\hline Metionina + Cistina $(\mathrm{Met}+\mathrm{Cys})$ & 1,14 & 1,16 & 1,17 & 1,19 & 1,21 \\
\hline
\end{tabular}

${ }^{1}$ Baseados nos valores de energia e digestível propostos por NRC (1993), Boscolo et al. (2002), Meurer et al. (2003) e Pezzato et al. (2002).

2 Baseados nos valores de proteína digestível proposto por Hayashi et al. (2002).

1 Values of digestible energy from NRC (1993), Boscolo et al. (2002), Meurer et al., 2003), and Pezzato et al. (2002) data.

2 Values of digestible protein from Hayashi et al. (2002) data.

por Boscolo (2003), que avaliou o desempenho de tilápia-do-nilo na fase de reversão sexual alimentadas com rações contendo diferentes níveis de FT $(0,5,10$, 15 e $20 \%$ ) e não observou diferenças no desempenho dos animais, e também Signor et al. (2004), que avaliaram rações com níveis $(0 ; 5 ; 10$ e $15 \%$ de FT; $0 \%$ de FT + suplementação com metionina) e também não observaram diferenças no desempenho de alevinos de tilápia-do-nilo. Resultado semelhante também foi observado por El-Sayed (1998), que verificou que a substituição de farinha de peixe pela de resíduos da industrialização de camarão para tilápias vermelhas (O. hornorum $\mathrm{X} O$. niloticus) na fase inicial não prejudicou o ganho de peso e a eficiência alimentar.

$\mathrm{O}$ CF apresentou diferenças $(\mathrm{P}<0,05)$ entre os tratamentos, observando-se melhores resultados nos tratamentos com FT e suplementação com metionina. O pior resultado $(\mathrm{P}<0,05)$ foi observado no tratamento sem FT, demonstrando que sua inclusão e a suplementação de metionina influenciou positivamente o CF em alevinos de piauçu, pois, com o fornecimento de FT na ração, aumentam-se o teor de metionina, que é um aminoácido essencial limitante para essa espécie.

Pelas análises realizadas pelo LRP (Linear Response Plateau), o CF apresentou um platô (Figura 1) no nível de $8,56 \%$ de inclusão de FT na ração.

Esse resultado comprova que esse alimento alternativo pode ser utilizado com sucesso na dieta de
L. Macrocephalus e está de acordo com outros estudos de substituição em rações para piauçu, como o de Soares et al.(2000), do farelo de soja pelo farelo de canola; e Nagae et al. (2002), do milho pelo milheto.

A CA e o FC apresentaram diferenças $(\mathrm{P}<0,05)$ em relação aos tratamentos, sendo observados os melhores resultados no tratamento com $15 \%$ de FT, que não diferiu daqueles com 5 e $10 \%$ de FT e $0 \%$ de FT suplementado com metionina. Para alevinos de

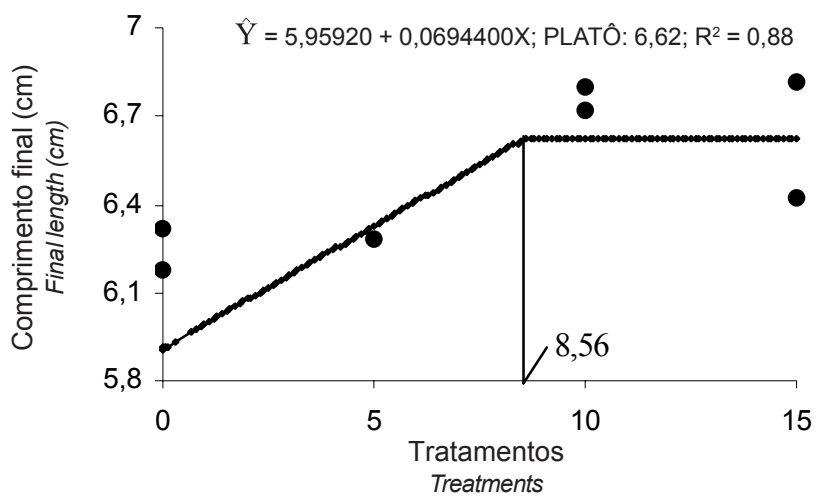

Figura 1 - Comprimento final médio de alevinos de piavuçu (L. macrocephalus) alimentados com diferentes níveis de farinha de resíduo de indústria de filetagem na ração.

Figure 1 - Average final length of piavuçu (L. macrocephalus) fed diets with increasing levels of tilapia filleting by-products meal. 
Tabela 3 - Desempenho de alevinos de piauçu (Leporinus macrocephalus) alimentados com rações com inclusão de diferentes níveis de farinha de resíduos de filetagem de tilápias (FT)

Table 3 - Performance of piauçu (Leporinus macrocephalus) fingerlings fed diets with increasing tilapia by-products meal (FT) levels

\begin{tabular}{|c|c|c|c|c|c|c|}
\hline \multirow[t]{2}{*}{$\begin{array}{l}\text { Parâmetro } \\
\text { Parameter }\end{array}$} & \multicolumn{5}{|c|}{$\begin{array}{l}\text { Níveis de farinha de tilápia (FT) } \\
\text { Tilapia by-products flour levels }(F T)\end{array}$} & \multirow[t]{2}{*}{$\mathrm{CV}(\%)$} \\
\hline & $0 \%$ & $5 \%$ & $10 \%$ & $15 \%$ & $0 \%+$ Met & \\
\hline $\begin{array}{l}\text { Peso inicial médio }(\mathrm{g}) \\
\text { Average initial weight }(\mathrm{g})\end{array}$ & $0,19 a$ & $0,19 \mathrm{a}$ & $0,19 a$ & $0,19 a$ & $0,19 \mathrm{a}$ & 2,21 \\
\hline $\begin{array}{l}\text { Peso final médio }(\mathrm{PF})(\mathrm{g}) \\
\text { Average final weight }(\mathrm{g})\end{array}$ & $4,13 \mathrm{a}$ & $3,25 \mathrm{a}$ & $4,08 \mathrm{a}$ & $3,52 \mathrm{a}$ & $3,92 \mathrm{a}$ & 24,84 \\
\hline $\begin{array}{l}\text { Ganho de peso médio }(\mathrm{GP})(\mathrm{g}) \\
\text { Average weight gain }(\mathrm{g})\end{array}$ & $3,94 a$ & $3,05 \mathrm{a}$ & $3,89 \mathrm{a}$ & $3,32 \mathrm{a}$ & $3,73 \mathrm{a}$ & 26,17 \\
\hline $\begin{array}{l}\text { Comprimento final médio }(\mathrm{CF})(\mathrm{cm})^{1} \\
\text { Average final length }^{1}\end{array}$ & $5,81 \mathrm{~b}$ & $6,49 \mathrm{a}$ & $6,74 \mathrm{a}$ & $6,88 \mathrm{a}$ & $6,46 a$ & 6,40 \\
\hline $\begin{array}{l}\text { Conversão alimentar aparente }{ }^{2}(\mathrm{CA}) \\
\text { Apparent feeding conversion }^{2}\end{array}$ & $1,38 \mathrm{a}$ & $1,18 \mathrm{~b}$ & $1,07 \mathrm{~b}$ & $1,02 b$ & $1,11 \mathrm{~b}$ & 11,06 \\
\hline $\begin{array}{l}\text { Fator de condição }{ }^{3} \text { (FC) } \\
\text { Condiction factor }^{3}\end{array}$ & $2,19 a$ & $1,28 b$ & $1,36 b$ & $1,09 b$ & $1,47 b$ & 36,69 \\
\hline $\begin{array}{l}\text { Sobrevivência (\%) (SO) } \\
\text { Survival (\%) }\end{array}$ & $96,00 \mathrm{a}$ & $100,00 \mathrm{a}$ & $100,00 \mathrm{a}$ & $100,00 \mathrm{a}$ & $96,00 \mathrm{a}$ & 5,75 \\
\hline
\end{tabular}

Média seguidas de letras distintas diferem a $5 \%$ de significância pelo teste de Ducan. Tratamentos: $0=$ sem inclusão de FT; $5=5 \%$ de $\mathrm{FT} ; 10=10 \%$ de FT; $15=15 \%$ de FT; $0+$ Met = suplementação com metionina.

Means followed by different letters differ at $5 \%$ of significance, Duncan test. Treatments: $0=$ without FT; $5=5 \%$ of FT; $10=10 \%$ of FT; $15=15 \%$ of FT; $0+$ Met $=$ supplementation with methionine.

1 Efeito linear (Linear effect) $-\hat{Y}=5,95920+0,0694400 X ; r^{2}=0,88$

${ }^{2}$ Efeito linear (Linear effect) $-\hat{Y}=1,34014-0,0235625 X ; r^{2}=0,92$.

3 Efeito linear (Linear effect) $-\hat{\mathrm{Y}}=1,96334-0,0645095 \mathrm{X} ; \mathrm{r}^{2}=0,73$.

tilápia-do-nilo, Signor et al. (2004) não observaram diferenças na CA com a inclusão de FT $(0 ; 5 ; 10$ e $15 \%$ de FT) e de $0 \%$ de FT suplementado com metionina. Boscolo (2003) observou melhor conversão alimentar de alevinos de tilápia com a inclusão de FT na dieta, não diferindo nos diferentes níveis de inclusão (6,75 e 13\% de FT).

Isso demonstra que as diferentes espécies aproveitam eficientemente este alimento protéico. Entretanto, em razão de sua elevada composição de cinzas com alta disponibilidade de cálcio e fósforo (Milamena, 2002; Boscolo, 2003), o excesso deste alimento na dieta pode causar eutrofização do meio ambiente (Hardy, 1996; Sugiura et al., 2000; Boscolo, 2003). Estes resultados demonstram que a inclusão de FT na dieta de L. macrocephalus melhorou $(\mathrm{P}<0,05)$ a $\mathrm{CA}$, podendo diminuir os custos de produção.

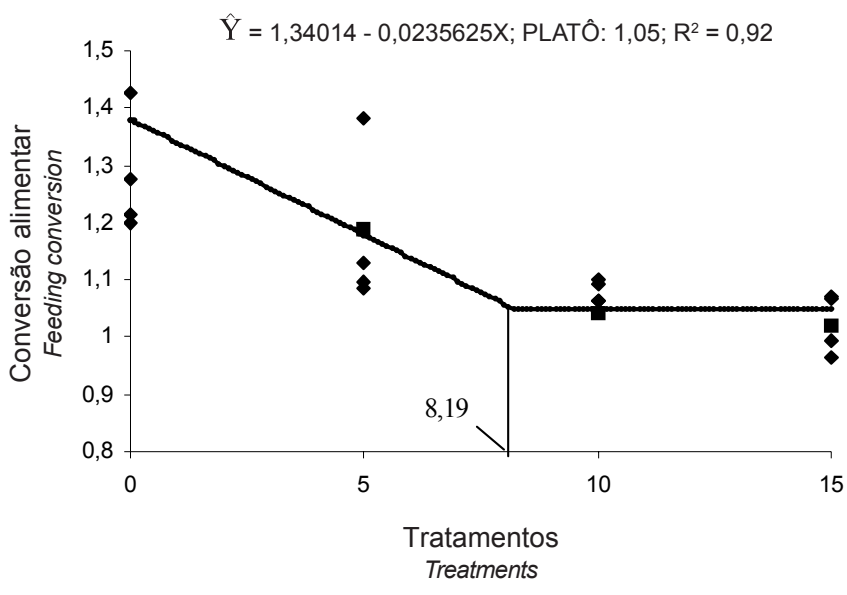

Figura 2 - Conversão alimentar aparente de alevinos de piavuçu alimentados com rações contendo diferentes níveis de farinha de resíduo de indústria de filetagem.

Figure 2 - Apparent feeding conversion of piavuçu fed different diets with increasing levels of tilapia filleting byproducts meal. 
$\mathrm{Na}$ análise de LRP realizada para a CA, foi observada diminuição linear com o platô (Figura 2) em $8,19 \%$ de inclusão de FT na dieta de piauçu.

Quanto ao fator de condição (FC), Boscolo (2003) não observou diferenças na tilápia-do-nilo, durante a fase de reversão sexual, entre os peixes alimentados com níveis de até $20 \%$ de inclusão de FT. Neste experimento, a inclusão de FT na ração de alevinos de piauçu influenciou negativamente $(\mathrm{P}<0,05)$ o $\mathrm{FC}$ dos animais em relação ao tratamento sem a inclusão de FT. A inclusão de FT na dieta não ocasionou diferença do tratamento com $0 \%$ de FT suplementado com metionina, indicando que o maior crescimento dos peixes pode estar relacionado ao melhor equilíbrio de aminoácidos disponíveis na dieta. Houve diferença no $\mathrm{CF}$ dos peixes $(\mathrm{P}<0,05)$, enquanto o $\mathrm{PF}$ e GP não apresentaram variação, indicando que estes cresceram mais e estavam mais magros.

Dois fatores podem ter influenciado esses resultados: os peixes do tratamento sem inclusão de FT estavam mais gordos em razão do desbalanco aminoácidico, uma vez que, com o aumento da inclusão de FT, houve maior disponibilidade de metionina e, conseqüentemente, maior crescimento; e/ou, ao serem submetidos ao arraçoamento limitado a $10 \%$ da biomassa com acréscimo de 5\% sobre o peso da ração a cada três dias, os peixes dos tratamentos com inclusão de FT e suplementação com metionina, embora estivessem se alimentando com ração com o melhor balanço aminoacídico e apresentassem maior comprimento, não receberam quantidade suficiente, pois, nesses tratamentos, foram registrados os piores índices de conversão alimentar.
Não foi observada diferença na taxa de sobrevivência, indicando que a inclusão de FT em até 15\% e a suplementação de metionina não prejudicaram a sobrevivência dos peixes. Resultados idênticos foram observados por Soares et al. (2000), ao substituírem parcial e totalmente o farelo de soja pelo farelo de canola, e Nagae et al. (2002), ao substituírem parcialmente o milho pelo milheto.

A suplementação com metionina não provocou diferenças para as variáveis $\mathrm{PF}, \mathrm{CF}, \mathrm{GP}, \mathrm{CA}, \mathrm{SO}$ e FC, em comparação à inclusão de FT. Os resultados demostraram que o piauçu aproveita bem os aminoácidos da dieta, corroborando os relatos de Soares et al. (2000), que observaram diferenças $(\mathrm{P}<0,05)$ no desempenho de alevinos de piauçu, ao substituírem parcial e totalmente o farelo de soja pelo farelo de canola na dieta.

Os melhores resultados apresentados pelos tratamentos com a inclusão de FT estão de acordo com aqueles reportados por Bellal \& Assem (1995), que substituíram fontes vegetais por fontes de origem animal, que possuem melhor digestibilidade da energia e proporcionam melhor desempenho aos peixes. A melhor taxa de conversão alimentar encontrada mostra que a FT é um excelente alimento e pode ser utilizada na formulação de rações para esta espécie.

Aminoácidos livres purificados são adicionados às rações dos peixes para corrigir sua deficiência de um ou mais aminoácidos. Muitas espécies os utilizam eficientemente, como O. niloticus (Viola et al., 1994; Furuya, 2000), Cyprinus carpio (Aoe et al., 1970; Pongmaneerat et al., 1987), Onchorynchus myskis (Runsey \& Ketola, 1975; Kaushik \& Luquet, 1980;

Tabela 4 - Composições percentual e química da carcaça de Leporinus macrocephalus alimentados com dietas contendo diferentes níveis de FT

Table 4 - Chemical composition (\%) of carcass of Leporinus macrocephalus fed diets with increasing tilapia filleting by-products meal (FT) levels

\begin{tabular}{|c|c|c|c|c|c|c|}
\hline \multirow[t]{2}{*}{$\begin{array}{l}\text { Variável } \\
\text { Variable }\end{array}$} & \multicolumn{5}{|c|}{$\begin{array}{l}\text { Nível de FT }(\%) \\
\text { FT level (\%) }\end{array}$} & \multirow[t]{2}{*}{ CV $(\%)$} \\
\hline & $0 \% \mathrm{FT}$ & $5 \% \mathrm{FT}$ & $10 \% \mathrm{FT}$ & $15 \% \mathrm{FT}$ & $0 \% \mathrm{FT}+\mathrm{met}$ & \\
\hline $\begin{array}{l}\text { Proteína bruta }(\%)^{1} \\
\text { Crude protein }(\%)\end{array}$ & $70,12 b$ & $70,52 b$ & $77,30 \mathrm{a}$ & $75,88 \mathrm{a}$ & 73,57ab & 4,54 \\
\hline $\begin{array}{l}\text { Matéria mineral }(\%) \\
\text { Mineral matter }(\%)\end{array}$ & $12,55 \mathrm{a}$ & $12,94 \mathrm{a}$ & $14,02 \mathrm{a}$ & $12,78 \mathrm{a}$ & $12,46 a$ & 6,50 \\
\hline $\begin{array}{l}\text { Umidade }(\%) \\
\text { Moisture (\%) }\end{array}$ & $76,99 a$ & $76,36 a$ & $76,77 \mathrm{a}$ & $75,79 a$ & $76,48 \mathrm{a}$ & 0,81 \\
\hline
\end{tabular}

${ }^{1}$ Efeito linear (Linear effect) $-\hat{Y}=69,7294+0,456829 X ; r^{2}=0,75$. 


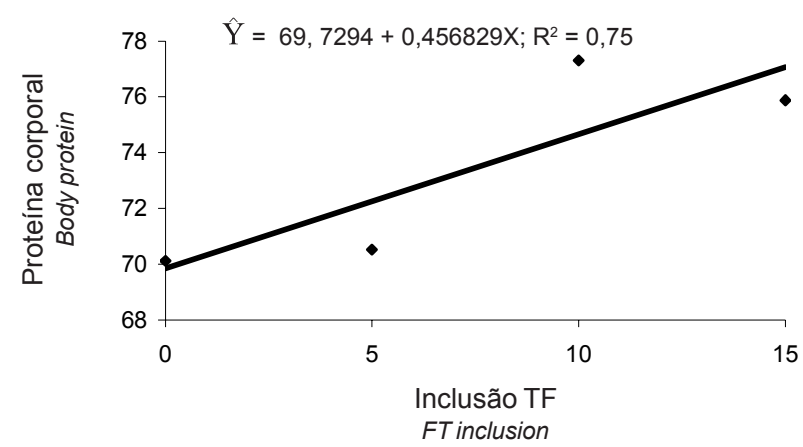

Figura 3 - Proteína na carcaça de alevinos de piavuçu L. macrocephalus alimentados com rações contendo diferentes níveis de farinha de resíduo de filetagem de tilápia FT.

Figure 3 - Protein in carcass piavuçu L. macrocephalus fed diets with increasing tilapia filleting by-products meal (FT) levels.
Médale et al., 1998) e Salmo salar (Storebakken et al., 1998). Neste experimento, observou-se melhor crescimento dos peixes com a inclusão de FT e/ou suplementação de metionina sintética na ração de L. macrocephalus em relação ao tratamento com suplementação de metionina. Pode-se inferir, portanto, que a exigência de metionina de piauçu é de $0,50 \%$.

Li \& Robinson (1998), ao suplementarem dietas para bagre do canal com lisina e metionina sintética ou sua combinação, observaram diminuição no consumo alimentar e no ganho de peso dos peixes, de modo semelhante a dietas com deficiência protéica. Os autores concluíram que o excesso de aminoácidos foi consumido como energia e não foi utilizado na síntese protéica, não proporcionando amento no peso. Isso pode ser explicado pela rápida absorção dos aminoácidos livres purificados, que pode resultar em catabolismo aminoacídico, reduzindo a eficiência de sua utilização (Lovell, 1991).

Constam na Tabela 4 as composições percentual e química da carcaça dos peixes. Os animais alimentados com rações contendo FT apresentaram diferenças $(\mathrm{P}<0,05)$ na taxa de deposição de proteína corporal, com aumento linear (Figura 3). A maior taxa de proteína corporal foi observada nos peixes do tratamento com $10 \%$ de inclusão de FT e não diferiu da taxa dos tratamentos com $15 \%$ e $0 \%$ de FT suplementado com metionina, diferindo, no entanto daquela registrada $(\mathrm{P}<0,05)$ nos demais tratamentos. Esses resultados demonstram que a inclusão de FT na dieta de
L. macrocephalus, além de não prejudicar seu desempenho, aumentou o nível de proteína corporal, proporcionando melhor qualidade nutricional do pescado.

A matéria mineral (MM) da carcaça não apresentou diferenças entre os tratamentos, comprovando que os diferentes níveis de inclusão de FT na dieta não influenciaram a deposição de minerais. Também não foram observadas diferenças no percentual de umidade nos peixes dos diferentes tratamentos.

Neste experimento, avaliou-se a inclusão de FT em substituição ao farelo de soja para alevinos de L. macrocephalus, a qual se apresenta, segundo análises de composição química realizadas por Boscolo (2003), como um alimento protéico de excelente qualidade para ser utilizado na alimentação de tilápias-donilo (O. Niloticus). Sua utilização na dieta de piauçu L. macrocephalus proporcionou melhoria significativa no desempenho e na conversão alimentar.

\section{Conclusões}

Conclui-se que a FT pode ser incluída em níveis de até $15 \%$ em rações para alevinos de piauçu e aquelas que têm o farelo de soja como principal fonte de proteína devem ser suplementadas com metionina sintética para melhor desempenho, conversão alimentar aparente e deposição de proteína na carcaça dos peixes.

\section{Literatura Citada}

AOE, H.; MASUDA, I.; ABE, I. et al. Nutrition of protein in young carp: I. Nutritive value of free amino acids. Bulletin Japanese Society Science Fish, v.36, p.407-413, 1970.

ANDRIAN, I.F.; DÓRIA, C.R.C.; TORRENTE, G. et al. Espectro alimentar e similaridade na composição da dieta de quatro espécies de Leporinus (Characiformes, Anostomidae) do rio Paraná (22ำ' $\left.10^{\prime}-22^{\circ} 50^{\prime} \mathrm{S} / 53^{\circ} 10^{\prime}-53^{\circ} 40^{\prime} \mathrm{W}\right)$, Brasil. Revista UNIMAR, v.16, p.97-106, 1994 (Suplemento 3).

ANTUNES, S.A. Recentes avanços e perspectivas da industrialização do pescado de água doce. In: SIMPÓSIO SOBRE MANEJO E NUTRIÇÃO DE PEIXES, 2., Piracicaba. Anais... Piracicaba: Colégio Brasileiro de Nutrição Animal, 1997. p.131-136.

BELLAL, J.E.H.; ASSEM, H. Substution of soybean meal and oil for fish meal in pratical diets fed to channel catfish, Ictalurus punctatus (Rafinesque): effects on body composition. Aquaculture Research, v.26, p.141-145, 1995.

BOSCOLO, W.R.; HAYASHI, C.; MEURER, F. Digestibilidade aparente da energia e proteína das farinhas de resíduo da filetagem da tilápia do Nilo (Oreochromis niloticus), da corvina (Plagioscion squamosissimus) e farinha integral do camarão canela (Macrobrachium amazonicum) para a tilápia do Nilo. Revista Brasileira de Zootecnia, v.33, n.1, p.8-13, 2004. 
BOSCOLO, W.R.; HAYASHI, C.; MEURER, F. Digestibilidade aparente da energia e nutrientes de alimentos convencionais e alternativos para a tilápia do Nilo (Oreochromis niloticus, L.). Revista Brasileira de Zootecnia, v.13, n.2, p.539-545, 2002a.

BOSCOLO, W.R. Farinha de resíduos da industria de filetagem de tilápia na alimentação da tilápia do Nilo (Oreochromis niloticus). Maringá: Universidade Estadual de Maringá, 2003. 83p. Tese (Dourorado em Zootecnia) - Universidade Estadual de Maringá, 2003.

BOSCOLO, W.R.; HAYASHI, C.; DEIDEN, A. et al. Farinha de vísceras de aves em rações para a tilápia do Nilo (Oreochromis niloticus L.) durante a fase de reversão sexual. In: CONGRESSO BRASILEIRO DE AQUICULTURA, 12., Goiânia. Anais... Goiânia: 2002. p.118.

BOYD, C. Water quality in ponds for aquaculture. Alabama: Birmingham Publiscing, 1990. 482p.

EL-SAYED, A.F.M. Total replacement of fish meal with animal protein sources in Nile tilapia Oreochromis niloticus (L.) feeds. Aquaculture Research, v.179, n.4, p.275-280, 1998.

FURUYA, W.M.; PEZZATO, L.E.; BARROS, M.M. Use of ideal protein concept for precision formulation of amino acid levels in diets with and without dicalcium phosphate for juvenile Nile tilapia (Oreochromis niloticus L.). Aquaculture Research, 2004 (em avaliação).

FURUYA, W.M. Digestibilidade aparente de aminoácidos e substituição da proteína da farinha de peixe pela proteína do farelo de soja com base no conceito de proteína ideal em rações para a tilápia do Nilo (Oreochromis niloticus L.). Botucatu: Universidade Estadual Paulista, 2000. 69p. (Tese de Doutorado em Zootecnia). Universidade Estadual Paulista, 2000.

HARDY, R.W. Alternate protein sources for salmon and trout diets. Animal Feed Science Technology, v.59, p.71-80, 1996.

HAYASHI, C.; BOSCOLO, W.R.; SOARES, C.M. et al. Exigência de proteína digestivel para larvas de tilápia do Nilo (Oreochromis niloticus), durante a reversão sexual. Revista Brasileira de Zootecnia, v.31, n.2, p.823-828, 2002.

HAYASHI,C.; BOSCOLO,W.R.; SOARES,C.M. et al. Uso de diferentes graus de moagem dos ingredientes em dietas para a tilapia do Milo (Oreochromis niloticus L.) na fase de crescimento. Acta Scientiarum, v.21, n.3, p.733-737,1999b.

HAYASHI, C.; SOARES, C.M.; BOSCOLO, W.R. et al. Utilização de polpa cítrica em dietas para o piavuçu (Leporinus macrocephalus, L.) na fase inicial. In: CONGRESSO BRASILEIRO DE ENGENHARIA DE PESCA, 11., CONGRESSO LATINO-AMAERICANO DE ENGENHARIA DE PESCA, 1., 1999, Olinda. Anais... Olinda: CONBEP/ CONLAEP, 1999a. p.211-219.

KAUSHIK, S.J.; LUQUET, P. Influence of bacterial protein incorporation and of sulphur amino acid supplementation to such diets on growth of rainbow trout. Aquaculture, v.19, p.163-175, 1980.

LOVELL, T. Nutrition of aquaculture species. Journal of Animal Science, v.69, p.4193-4200, 1991.

LI, M.H.; ROBINSON, E.H. Effects of suplemental lysine and methionine in low protein diets on weght gain and body composition of yong channel catfish Ictalurus punctatus. Aquaculture, v.163, p.297-307, 1998.

MÉDALE, F.; BOUJARD, T.; VALLÉE, F. et al. Voluntary feed intake, nitrogen and fosphorus losses rainbow trout (Oncorinchus mykiss) fed increasing dietary levels of soy protein concentrate. Aquaculture Living Resourse, v.4, p.239-246, 1998.
MEURER, F.; HAYASHI, C.; BOSCOLO, W.R. Digestibilidade aparente dos nutrientes e energia de alguns alimentos protéicos para juvenis de tilápia do Nilo (Oreochromis niloticus). Revista Brasileira de Zootecnia, v.32, n.6, p.1801-1809, 2003 (supl. 2).

MILLAMENA, O.M. Replacement of fish meal by animal byproduct meals in a practical diet for grow-out culture of grouper Epinephelus coiodes. Aquaculture, v.204, p.75-84, 2002.

NAGAE, M.Y.; HAYASHI, C.; SOARES, C.M. et al. Inclusão do milheto (Ppennisetum americanum) em rações para alevinos de peiavuçú (Leporinus macrocephalus). Revista Brasileira de Zootecnia, v.31, n.5, p.1875-1880, 2002.

NATIONAL RESEARCH COUNCIL - NRC. Nutrient requeriments of fish. Washington, D.C.: National Academy Press, 1993. 114p.

PEZZATO, L.E.; MIRANDA, E.C.; BARROS, M.M. et al. Digestibilidade aparente de ingredientes pela tilápia do Nilo (Oreochromis niloticus). Revista Brasileira de Zootecnia, v.31, n.4, p.1595-1604, 2002.

PONGMANEERAT, J.; WATANABE, T.; TAKEUSHI, T. et al. Use of different protein meals as partial or total substitution for fish meal in carp diets. Japanese Society Science Fish, v.59, 1249-1257, 1987.

RIBEIRO, R.P. Desenvolvimento, sobrevivência e seletividade alimentar de pós larvas de piavuçu, Leporinus macrocephalus, (OSTEICHTHYES, ANOSTOMIDAE), submetidos a diferentes dietas, associados aos fatores abióticos e bióticos. Maringá: Universidade Estadual de Maringá, 1999. 50 p. Tese (Doutorado em Ecologia de Ambientes Aquáticos Continentais) - Universidade Estadual de Maringá, 1999.

RUMSEY, G.L.; KETOLA, H.G. Amino acid supplementation of casein in diets of Atlantic salmon (Salmo salar) fry and of soybean meal for rainbow trout (Salmo gairdneri) fingerlings. Journal Fish Research Board Canada, v.32, p.442, 1975.

SIGNOR, A.; FEIDEN, A.; BOSCOLO, W.R. et al. Farinha de resíduo da filetagem de tilápia em rações para alevinos de tilápia do Nilo Oreochromis niloticus. In: Reunião Anual da REUNIÃO ANUAL DA SOCIEDADE BRASILEIRA DE ZOOTECNIA, 41., 2004, Campo Grande. Anais... Campo Grande: Sociedade Brasileira de Zootecnia/Unipress, [2004]. CD-ROM.

SILVA, D.J. Análise de alimentos (Métodos químicos e biológicos) Viçosa, MG: Universidade Federal de Viçosa, 1990. $166 \mathrm{p}$.

SILVA, A.C. Alimentação natural de quatro espécies de peixes da família Anostomidae (Ostariophysi, Characiformes) do Rio Araguari, Bacia do Parnaiba, MG. In: ENCONTRO ANUAL DE AQÜICULTURA DE MINAS GERAIS, 6., 1988, Belo Horizonte. Resumos... Belo Horizonte: 1988. p.1.

SIPAÚBA-TAVARES, L.H.S. Limnologia aplicada à aqüicultura. Jaboticabal: Funep, 1995. 72p.

SOARES, C.M.; HAYASHI, C.; FURUYA, V.R.B. et al. Substituição parcial e total da proteína do farelo de soja pela proteína do farelo de canola na alimentação de alevinos de piavuçu (Leporinus macrocephalus, L.). Revista Brasileira de Zootecnia, v.29, n.1, p.15-22, 2000.

SOARES, C.M. Farelo de canola na alimentação de alevinos de piavuçu (Leporinus macrocephalus L.) e de carpa-capim (Ctenopharyngodon idella V.). Maringá: Universidade Estadual de Maringá, 1997. 40p. Dissertação (Mestrado em Zootecnia) - Universidade Estadual de Maringá, 1997. 
STOREBAKKEN, T.; KVIEN, I.S.; SHEARER, K.D. et al. The apparent digestibility of diets containing fish meal, soybean meal or bacterial meal fed to Atlantic salmon (Salmo salar): evaluation of different feacal collection metthods. Aquaculture, v.169, n.3-4, p.195-210, 1998.

SUGIURA, S.H.; BABBITT, J.K.; DONG, F.M. et al. Utilization of fish and animal by-product meals in low-pollution feeds for rainbow trout Oncorhynchus mykiss (Walbaum). Aquaculture Research, v.31, p.585-593, 2000.

UNIVERSIDADE FEDERAL DE VIÇOSA - UFV. SAEG Sistema para Análises Estatísticas e Genéticas. Versão 7.1 Viçosa: 1997. 150p (Manual do usuário).
VIOLA, S.; ANGEONI, H.; LAHAV, E. Present limits of protein sparing by amino acid supplementation of practical carp and tilapia feeds. Journal Aquaculture, v.46, p.203-211, 1994.

Recebido em: 21/12/04

Aceito em: 08/06/05 